\title{
Magnesium Ammonium Phosphate Urolithiasis
}

National Cancer Institute

\section{Source}

National Cancer Institute. Magnesium Ammonium Phosphate Urolithiasis. NCI

Thesaurus. Code C123030.

Urolithiasis in which the composition of the stone(s) is predominantly magnesium ammonium phosphate. 